
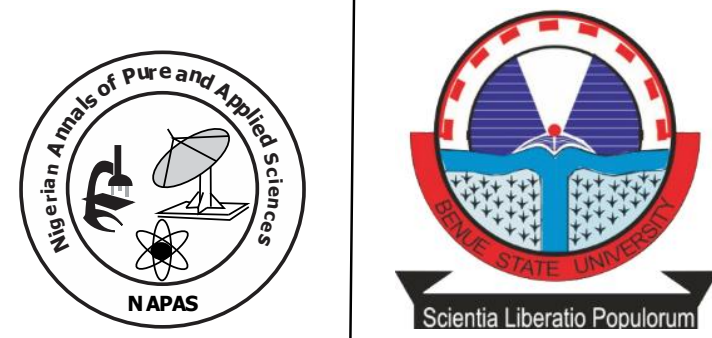

\title{
Measurement of Natural Radionuclides and Radon Gas Concentration in Surface Soll samples within Jalingo Metropolis, North East Nigeria.
}

\author{
${ }^{*}$ Sombo, T., Bibi, F. and Tyovenda, A. A. \\ Department of Physics, \\ University of Agriculture, Makurdi, Benue State. \\ Corresponding Email: jtsombo@gmail.com
}

doi: https//doi.org/10.46912/napas.233

\begin{abstract}
Activity concentrations of radionuclides $\left({ }^{226} \mathrm{Ra},{ }^{232} \mathrm{Th},{ }^{40} \mathrm{~K}\right)$ and radon gas in soil samples collected within Jalingo Metropolis were assessed by gamma spectrometric techniques using Na (TI) scintillation detector. The result showed an average activity concentration of ${ }^{226} \mathrm{Ra},{ }^{232} \mathrm{Th}$ and ${ }^{40} \mathrm{~K}$ to be $18.626 \pm 7.31$ $\mathrm{Bq} / \mathrm{kg}, 16.709 \pm 10.96 \mathrm{~Bq} / \mathrm{kg}$ and, $167.935 \pm 389.33 \mathrm{~Bq} / \mathrm{kg}$. The concentrations of ${ }^{226} \mathrm{Ra},{ }^{232} \mathrm{Th}$ were lower than the world average value while ${ }^{40} \mathrm{~K}$ was far higher that the recommended value.Most people in the study area use soil for building construction therefore, it was necessary to asses if there are any radiological hazards associated with the soil. This was achieved by determining Radium equivalent activity (Raeq), internal hazard index (Hin) and Annual effective dose rate. The result indicates that the indices are within normal limit. The Radon concentration in soil varies $11.126 \pm 1.315 \mathrm{kBq} / \mathrm{kg}$ to $30.374 \pm 3.331 \mathrm{kBq} / \mathrm{kg}$ with a mean value of $17.881 \pm 7.019 \mathrm{kBq} / \mathrm{kg}$ which is within the safety limits. Generally, the result showed that the soil in the study area might not pose major hazard to the members of the public.
\end{abstract}

Keywords: Radionuclides, Radon, Soil, Radioactivity, Environment. 


\section{Introduction}

Radiation is the energy which is transported either in the form of particles or electromagnetic waves through space or material medium. The natural sources of radiation exposure to humans are artificial (medical applications, fertility application, mining etc) and natural (terrestrial and cosmogenic radionuclides) both radiation sources lead to internal and external radiation exposure. External exposure occurs due to gamma decay of primordial radionuclides while internal exposure results from the inhalation of airborne contaminants oringestion of food and water contaminated by radionuclides [1].

The earth is naturally radioactive and about $90 \%$ of human radiation exposure arise from sources such as cosmic radiation, radon gas and terrestrial radionuclides. Their concentrations is dictated to a good degree by the underlying geological features of an area, its geographical location and anthropogenic activities [2] and [3]. Radon $\left({ }^{226} \mathrm{Ra}\right)$, a radioactive gas produced by the decay of naturally occurring radionuclide is a byproduct in the uranium $\left({ }^{238} \mathrm{U}\right)$ series. Its three naturally existing isotopes namely ${ }^{222} \mathrm{Rn},{ }^{220} \mathrm{Rn}$ and ${ }^{219} \mathrm{Rn}$ are distinctively known as Radon, Thoron and Actinon respectively [4].

Radon and natural radionuclides have become subject of interest in recent times because of their detrimental effects on human health [5]. Acute and chronic exposure to radiation can cause adverse health effects such as cataract, lesions and stochastic effects such as cancer induction and hereditary diseases[6] and [7].

\section{Materials}

Measurement of Natural radionuclide and Radon gas concentration in Jalingo surface soils was performed using Gamma spectrometry system NaI (TI) detector (model:802), 2mm sieve, Polyethylene sample bags, Nitric acid, and Multichannel etrex GPS meter.

\section{Surface Soil Samples Collection and Preservation}

The ten (10) soil samples were collected in a label polyethylene bag from the following areas Nukkai, Mile six, Mayogwai, Sabongari, NTA and along the bank of river Nukkai and Mayogwoi at a depth of $30 \mathrm{~cm}$, each sampling locations were carefully chosen to represent areas where human population is involve in various activities such as fishing, vegetable farming, extraction of building materials (sharp sand, gravel etc) and others. The
Jalingo's natural environment (soil, water, air) have not been subjected to radiological regulatory control just like other regions in Northern Nigeria. Thus, Data on radionuclides and radon concentrations insurface soils and public exposure are scanty. Consequently, there is lack of awareness and knowledge of the radiological hazards emanating from surface soil and other components of environment. Hence, the urgent need toascertain the radiological safety level of surface soils in Jalingo Metropolis

\section{Materials and Method Study Area.}

Jalingo, the state capital of Taraba State has an estimated population of 11800(National Population Census,2006). Inhabitants of Jalingo are civil servants and farmers, fishermen and traders. Figure 1 is the map of Jalingo metropolis.

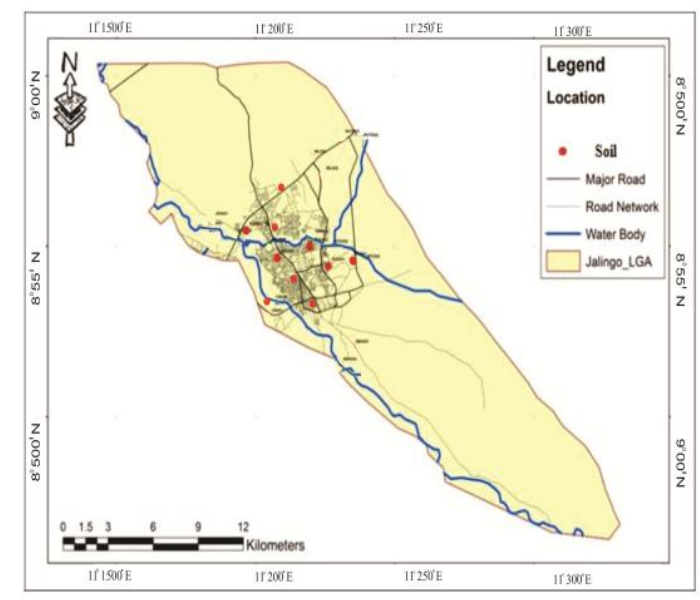

Figure 1: Map of Jalingo showing the sampling areas.

samples were sun dried to constant weight and sieved using $2 \mathrm{~mm}$ mesh to obtain a fine-powdered texture that will give an equilibrium level with the detector. The samples were then send to the laboratory at University of Ibadan for Radionuclides analysis.

\section{Activity measurement}

The activity concentrations of ${ }^{40} \mathrm{~K},{ }^{226} \mathrm{Ra}$, and ${ }^{232} \mathrm{Th}$ in the prepared soil samples were measured using the gamma spectrometric technique. The gamma spectrometric system consists of a $7.62 \times 7.62 \mathrm{~cm} \mathrm{Na}(\mathrm{TI})$ scintillation detector (Bicron Corp model 3M/3), encapsulated in a 5.5-cm-thick lead shield to reduce environmental background radiation. The detector was coupled to a preamplifier (Bicron Corp Model PA-14), an amplifier (Canberra Model, 2022), and an analogue-to-digital converter (ADC) (Canberra 
Model 8075), which supplied an output to a Canberra S100 multi-channel analyzer (MCA). The activity concentration of ${ }^{40} \mathrm{~K}$ was measured from its gamma-ray energy of $1460 \mathrm{keV}$, and the transition lines of $1120.3 \mathrm{keV}$ for ${ }^{214} \mathrm{Bi}$ and 911 $\mathrm{keV}$ for ${ }^{228} \mathrm{Ac}$ were applied for ${ }^{226} \mathrm{Ra}\left({ }^{238} \mathrm{U}\right.$ series $)$ and ${ }^{228} \mathrm{Ra}\left({ }^{232} \mathrm{Th}\right.$ series), respectively.

A standard soil sample supplied by the International Atomic Energy Agency (IAEA), Vienna, Austria (Reference Material IAEA-375 for radionuclides and trace elements in soil), was used for the calibrations of the detector. The background radiation was considered as an empty container having the same geometry as the container of the standard sample and was counted for $25,200 \mathrm{~s}(7 \mathrm{~h})$. Each of the prepared soil samples was counted for $7 \mathrm{~h}$ to determine the activity concentration of the radionuclides in them. The activity concentrations of the radionuclides in the samples were obtained using the comparative method according to Equation 1 [8]:

$\frac{A_{S}}{A_{S D}}=\frac{N_{S}}{N_{S D}}$

Where $A_{s}$ and $A_{S D}$ are the activity concentration $(\mathrm{Bq} / \mathrm{kg})$ of the sample and the reference sample, respectively, and $\mathrm{N}_{S}$ and $\mathrm{N}_{\mathrm{SD}}$ are the net count rates under the region of interest for the sample and the reference (Standard) sample, respectively. The counting was performed in the Radiological Laboratory of Centre for Energy, Research and Development (CERD) University of Ibadan.

\section{Data Evaluation}

The activity concentration of NORMs in soil samples

The activity concentration of ${ }^{226} \mathrm{Ra},{ }^{232} \mathrm{Th}$ and ${ }^{40} \mathrm{~K}$ were calculated using the following equation 2 [9].

$\mathrm{A}_{\mathrm{sp}}=\frac{N_{\mathrm{sam}} * \exp (\lambda T d)}{P \epsilon . T c \times \varepsilon \times M_{\mathrm{sam}}}$

$\mathrm{N}_{\mathrm{sam}}$ - Net counts of radionuclides in the sample

$\mathrm{P} \epsilon$ - Gamma ray emission probability (gamma yield)

$\varepsilon-$ Total counting efficiency of the detector system

$\mathrm{T}_{\mathrm{d}}$ - delay time between sampling and counting $\exp (\lambda T d)-$ correlation factor between sampling and counting

Tc - sampling counting time

$\mathrm{M}_{\text {sam }}$ - mass of sampling (ka) or volume (L)

\section{Assessment of radiological hazards in soil}

The radiation hazards due to the natural nuclides ${ }^{226} \mathrm{Ra},{ }^{232} \mathrm{Th}$ and ${ }^{40} \mathrm{~K}$ were assessed by various radiation hazards indices.

i. Radium equivalent activity (Raeq); In the present study, the radium equivalent activity $\left(\mathrm{Ra}_{\mathrm{eq}}\right)$ is given by the equation 3 [10].

$\mathrm{Ra}_{\mathrm{eq}}(\mathrm{Bq} / \mathrm{Kg})=0.077 \mathrm{C}_{\mathrm{k}}+\mathrm{C}_{\mathrm{Ra}}+1.43 \mathrm{C}_{\mathrm{Th}}$ (3)

Where $C_{k}, C_{R a}$ and $C_{t h}$ are the activity of Potassium, Radium and Thorium.

ii. Internal hazards index $\left(\mathbf{H}_{\text {in }}\right)$ : Internal radiation hazards index is given by the equation (4)

$$
\mathrm{H}_{\text {in }}=\mathrm{C}_{\mathrm{Ra}} / 185+\mathrm{C}_{\mathrm{Th}} / 259+\mathrm{C}_{\mathrm{K}} / 4810
$$

\section{Estimation of annual effective dose (AED) of NORMs in soil}

To evaluate the year - long effective dose rates, the conversion coefficient from absorbed dose in the air to effective dose $\left(0.75 \mathrm{vGy}^{-1}\right)$ and outdoor occupancy factor $\left(0.25 \mathrm{vGy}^{-1}\right)$ and $\left(0.85 \mathrm{vGy}^{-1}\right)$ suggested by [1] was applied.

Indoor Effective Dose Rate $\left(\mathrm{msvy}^{-1}\right)=$ Dose Rate $\left(\mathrm{nGyh}^{-1}\right.$ x 8760) h x 0.8 x $0.7 \mathrm{svGy}^{-1} \mathrm{x}$ $10^{-6}$

Outdoor Effective Dose rate $\left(\mathrm{msvy}^{-1}\right)=$ Dose rate $\left(\mathrm{nGyh}^{-1} \times 8760 \mathrm{~h}\right) \times 0.2 \times 0.7 \mathrm{svGy}^{-1} \times 10^{-6}$

\section{Radon in the soil}

The activity concentration of radon gas in the soil samples were calculated based on the radium (R-226) concentration using equation (7) [9].

$\mathrm{C}_{\mathrm{Rn}}=\mathrm{C}_{\mathrm{Ra}}-226 \times \mathrm{f} \times \rho \epsilon \times \varepsilon^{-1}(1-\varepsilon)\left[\mathrm{m}\left[\mathrm{K}_{\mathrm{T}}-1\right]+1\right]^{-1}$

Where

$\mathrm{C}_{\mathrm{Rn}}$ - is the concentration of radon-222 in $\left(\mathrm{Bq} / \mathrm{m}^{3}\right)$ $\mathrm{C}_{\mathrm{Ra}}$ - activity concentration of dry mass of $226 \mathrm{Ra}$ in soil $(\mathrm{Bq} / \mathrm{Kg})$

$\mathrm{f}-$ soil emanation factor for $\mathrm{Rn} 222=0.2$

$\rho_{\mathrm{s}}-$ density of soil $\left(1600 \mathrm{Kg} / \mathrm{m}^{3}\right)$

$\varepsilon-$ is the soil porosity $(0.25)$

$K_{\mathrm{T}}$ - is the radon partition coefficient between water and air phases and if the soil samples are dried before measurement, then, $\mathrm{m}=0$, the last term in equation (7) disappears.

$m-$ is the porosity fraction, $\mathrm{m}=0$ for dry soil.

\section{Results and Discussion}

The result of activity concentration of radionuclide (Ra-226, Th-232 and K-40) and Radon gas; Radium equivalent index, internal hazard index, Annual effective dose and the correlation between Ra-226 and Rn-222 in the 
surface soil samples are presented in Table $1-5$

and figure 2 below;

Table 1: Concentration of Natural Radionuclides In Soil Samples (Bq/Kg)

\begin{tabular}{llll}
\hline Sample Location & Ra-226 & Th-232 & K-40 \\
\hline NUK-1 & $11.59 \pm 1.37$ & $2.39 \pm 0.14$ & $2152.68 \pm 109.95$ \\
NUK-2 & $14 \pm 1.79$ & $21.36 \pm 1.28$ & $1804.19 \pm 92.39$ \\
MLS-1 & $i 1 \pm 1.50$ & $10.39 \pm 0.62$ & $1035.79 \pm 53.39$ \\
MLS-2 & $14 \pm 1.60$ & $11.45 \pm 0.63$ & $1020.89 \pm 52.24$ \\
SBG-1 & $i 4 \pm 3.70$ & $13.44 \pm 0.81$ & $1669.47 \pm 85.49$ \\
SBG-2 & $16 \pm 2.60$ & $13.55 \pm 0.26$ & $1517.59 \pm 80.59$ \\
MYG-1 & $16 \pm 1.32$ & $4.43 \pm 0.56$ & $2101.53 \pm 89.26$ \\
MYG-2 & $16 \pm 1.23$ & $27.21 \pm 1.23$ & $1889.23 \pm 80.34$ \\
NTA-1 & $i 4 \pm 3.47$ & $37.45 \pm 2.80$ & $1848.46 \pm 82.45$ \\
NTA-2 & $i 2 \pm 2.73$ & $25.42 \pm 1.33$ & $1689.52 \pm 80.32$ \\
MIN & $\mathbf{i 9} \pm \mathbf{1 . 3 0}$ & $\mathbf{2 . 3 9} \pm \mathbf{0 . 1 4}$ & $\mathbf{1 0 2 0 . 8 9} \pm \mathbf{5 2 . 2 4}$ \\
MAX & & & \\
& $\mathbf{i 4} \pm \mathbf{3 . 4 7}$ & $\mathbf{3 7 . 4 5} \pm \mathbf{2 . 8 0}$ & $\mathbf{2 1 5 2 . 6 8} \pm \mathbf{1 0 9 . 9 5}$ \\
AVERAGE \pm STDV & $\mathbf{i 2 6} \pm \mathbf{7 . 3 1}$ & $\mathbf{1 6 . 7 0 9 \pm 1 0 . 9 6}$ & $\mathbf{1 6 7 2 . 9 3 5} \pm \mathbf{3 8 9 . 3 3}$ \\
\hline
\end{tabular}

Table 2: Radium Equivalent Index $\left(\mathrm{Ra}_{\mathrm{eq}}\right)$ and Internal Hazard Index $\left(\mathrm{H}_{\mathrm{in}}\right)$

\begin{tabular}{lrc}
\hline Sample Location & Raeq $(\mathbf{B q} / \mathbf{K g})$ & Hin $(\mathbf{B q} / \mathbf{K g})$ \\
\hline NUK-1 & $180.764 \pm 10.036$ & $0.519 \pm 0.031$ \\
NUK-2 & $184.507 \pm 10.334$ & $0.539 \pm 0.033$ \\
MLS-1 & $107.224 \pm 6.498$ & $0.324 \pm 0.216$ \\
MLS-2 & $109.322 \pm 6.523$ & $0.334 \pm 0.022$ \\
SBG-1 & $169.308 \pm 11.441$ & $0.515 \pm 0.041$ \\
SBG-2 & $161.69 \pm 8.613$ & $0.505 \pm 0.032$ \\
MYG-1 & $181.113 \pm 8.994$ & $0.524 \pm 0.028$ \\
MYG-2 & $197.841 \pm 9.175$ & $0.571 \pm 0.028$ \\
NTA-1 & $227.525 \pm 22.403$ & $0.700 \pm 0.070$ \\
NTA-2 & $194.064 \pm 10.162$ & $0.599 \pm 0.036$ \\
MIN & $\mathbf{1 0 7 . 2 2 4} \pm \mathbf{6 . 4 9 8}$ & $\mathbf{0 . 3 2 4 \pm 0 . 2 1 6}$ \\
MAX & $\mathbf{2 2 7 . 5 2 5} \pm \mathbf{2 2 . 4 0 3}$ & $\mathbf{0 . 7 0 0 \pm 0 . 0 7 0}$ \\
AVERAGE \pm STDV & $\mathbf{1 7 1 . 3 3 5 8} \pm \mathbf{3 7 . 6 9 3}$ & $\mathbf{0 . 5 1 3} \pm \mathbf{0 . 1 1 2}$ \\
\hline
\end{tabular}

Table 3: Annual Effective Dose Due to Ingestion of Norms (Ra-226, Th-232 and K-40) in Soil Samples

\begin{tabular}{|c|c|c|c|}
\hline Sample location & Indoors & Outdoors & 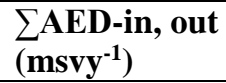 \\
\hline NUK-1 & $0.481 \pm 0.182$ & $0.120 \pm 0.046$ & $0.601 \pm 0.228$ \\
\hline NUK-2 & $0.468 \pm 0.156$ & $0.117 \pm 0.045$ & $0.585 \pm 0.201$ \\
\hline MLS-1 & $0.272 \pm 0.090$ & $0.068 \pm 0.023$ & $0.340 \pm 0.113$ \\
\hline MLS-2 & $0.276 \pm 0.089$ & $0.069 \pm 0.025$ & $0.645 \pm 0.114$ \\
\hline SBG-1 & $0.431 \pm 0.147$ & $0.108 \pm 0.037$ & $0.539 \pm 0.151$ \\
\hline SBG-2 & $0.409 \pm 0.136$ & $0.102 \pm 0.034$ & $0.511 \pm 0.170$ \\
\hline MYG-1 & $0.430 \pm 0.149$ & $0.118 \pm 0.037$ & $0.548 \pm 0.186$ \\
\hline MYG-2 & $0.500 \pm 0.150$ & $0.125 \pm 0.034$ & $0.625 \pm 0.184$ \\
\hline NTA-1 & $1.004 \pm 0.159$ & $0.161 \pm 0.039$ & $1.165 \pm 0.198$ \\
\hline NTA-2 & $0.486 \pm 0.115$ & $0.121 \pm 0.034$ & $0.607 \pm 0.149$ \\
\hline MIN & $0.272 \pm 0.09$ & $0.068 \pm 0.023$ & $0.340 \pm 0.113$ \\
\hline MAX & $1.004 \pm 0.159$ & $0.161 \pm 0.039$ & $1.165 \pm 0.198$ \\
\hline AVERAGE \pm STDV & $0.476 \pm 0.203$ & $0.111 \pm 0.027$ & $0.591 \pm 0.211$ \\
\hline
\end{tabular}

Table 4: Activity Concentration of Radon Gas (Rn-222) Calculated from the Soil Samples

\begin{tabular}{lrr}
\hline Sample location & Ra-226 Bq/Kg & Rn222(KBq/m) \\
\hline NUK-1 & $11.59 \pm 1.370$ & $11.126 \pm 1.315$ \\
NUK-2 & $15.04 \pm 1.790$ & $14.438 \pm 1.718$ \\
MLS-1 & $12.61 \pm 1.500$ & $12.106 \pm 1.440$ \\
MLS-2 & $14.34 \pm 1.600$ & $13.766 \pm 1.536$ \\
SBG-1 & $21.54 \pm 3.700$ & $20.678 \pm 3.552$ \\
SBG-2 & $25.46 \pm 2.600$ & $24.442 \pm 2.496$ \\
MYG-1 & $12.96 \pm 1.320$ & $12.442 \pm 1.267$ \\
MYG-2 & $13.46 \pm 1.230$ & $12.923 \pm 1.181$ \\
NTA-1 & $31.64 \pm 3.470$ & $30.374 \pm 3.331$ \\
\hline
\end{tabular}




\begin{tabular}{lrr}
\hline NTA-2 & $27.62 \pm 2.730$ & $26.515 \pm 2.621$ \\
MIN & $\mathbf{1 1 . 5 9} \pm \mathbf{1 . 3 7 0}$ & $\mathbf{1 1 . 1 2 6} \pm \mathbf{1 . 3 1 5}$ \\
MAX & $\mathbf{3 1 . 6 4 \pm 3 . 4 7 0}$ & $\mathbf{3 0 . 3 7 4} \pm \mathbf{3 . 3 3 1}$ \\
AVERAGE \pm STDV & $\mathbf{1 8 . 6 2 6} \pm \mathbf{7 . 3 1 1}$ & $\mathbf{1 7 . 8 8 1} \pm 7.019$ \\
\hline
\end{tabular}

Table 5: Comparison of Soil Gas Radon-222 with other Studies around the World

\begin{tabular}{lllll}
\hline Country & Sample Location & $\begin{array}{l}\text { Measurement } \\
\text { techniques }\end{array}$ & $\begin{array}{l}\text { Concentration(R- } \\
\mathbf{2 2}) \mathbf{B q} / \mathbf{m}^{\mathbf{3}}\end{array}$ & Reference \\
\hline Nigeria & Jalingo & NaI(TI) & $11,126-30,374$ & This study \\
Ghana & Mine & HPGe & $12,500-41,300$ & Faanu, $(2011)$ \\
Ghana & Fault & Alpha Guard & $9,910-42,010$ & Amponsah P, (2008) \\
Sudan & Soil & SSNTD & $5,500-15,100$ & Elmonien, (2015) \\
India & - & RAD7 Radon meters & $3,200-17,200$ & Mehra et al, (2015) \\
Russia & - & - & $17,000-24,000$ & Iakovleva et al, (2003) \\
Italy & Volc/mountain & RAD7 meters & $232-104,300$ & Giammanco et al, (2007) \\
Turkey & Geotherm area & SSNTD & $98-8594$ & Tabar et al, (2013) \\
India & & Upper siwalik & $11500-78470$ & Singh et al, (2010) \\
\hline
\end{tabular}

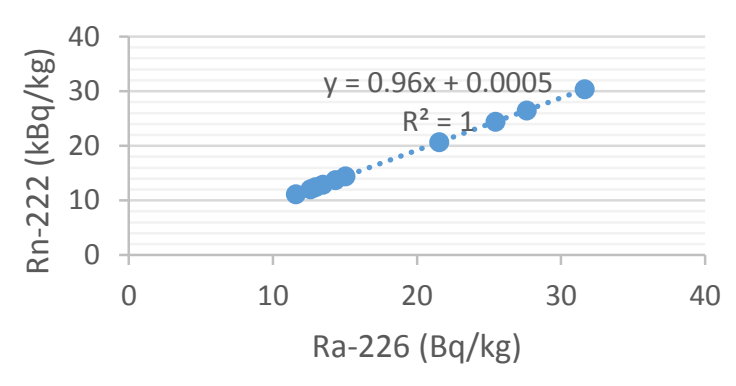

Figure 2: Correlation between Ra-226 and Rn-222 in soil sample

Table 1, shows that ${ }^{226} \mathrm{Ra}$ activity concentration ranges from $11.59 \pm 1.30$ to $31.64 \pm 3.47 \mathrm{~Bq} / \mathrm{Kg}$ with an average value of $18.626 \pm 7.31 \mathrm{~Bq} / \mathrm{Kg} ;{ }^{232} \mathrm{Th}$ concentration ranges from $2.39 \pm 0.14$ to $37.45 \pm 2.80 \mathrm{~Bq} / \mathrm{Kg}$ with an average value of $16.709 \pm 10.96 \mathrm{~Bq} / \mathrm{Kg}$ while ${ }^{40} \mathrm{~K}$ concentration ranges from $1020.89 \pm 52.24$ to $2152.68 \pm 109.95 \mathrm{~Bq} / \mathrm{Kg}$ with an average value of $1672.935 \pm 389.33 \mathrm{~Bq} / \mathrm{Kg}$. In comparison, ${ }^{226} \mathrm{Ra}$ and ${ }^{232} \mathrm{Th}$ concentrations were found to be below the world average value of 35 and $30 \mathrm{~Bq} / \mathrm{Kg}$. The low concentration might be attributed to low geochemical composition of uranium associated with sedimentary rock forming soils in the study area. The concentration of ${ }^{40} \mathrm{~K}$ were found to be far higher than the world average value of $400 \mathrm{~Bq} / \mathrm{Kg}$. Its high concentration may be due to their relative abundance in the environment and the application of fertilizer rich in ${ }^{40} \mathrm{~K}$ on farm lands within the metropolis.

The calculated Radium equivalent activity $\left(\mathrm{Ra}_{\mathrm{eq}}\right)$ values ranged from 107.224 \pm 6.498 to $227.525 \pm 22.403 \mathrm{~Bq} / \mathrm{Kg}$ with average value of $171.336 \pm 37.693 \mathrm{~Bq} / \mathrm{Kg}$ while the Internal Hazard Index $\left(\mathrm{H}_{\text {in }}\right)$ was found to range from $0.34 \pm 0.216$ to $0.700 \pm 0.070 \mathrm{~Bq} / \mathrm{Kg}$ with an average $0.513 \pm 0.112 \mathrm{~Bq} / \mathrm{Kg}$. This shows that the estimated value of $\mathrm{Ra}_{\mathrm{eq}}$ is less than the global limit of $370 \mathrm{~Bq} / \mathrm{Kg}$ and that of $\mathrm{H}_{\text {in }}$ is within the acceptable limit of 1(Table 2).

Table 3 shows the total annual effective dose due to external and internal gamma dose which ranged from $0.340 \pm 0.113$ to $1.165 \pm 0.198 \mathrm{mSy} / \mathrm{y}$ with an average of $0.591 \pm 0.211 \mathrm{mSv} / \mathrm{y}$ and is also below the world value of $1 \mathrm{mSvy}^{-1}$ [1].

The radon $(\mathrm{Rn}-222)$ concentration shown in Table 4 varies from $11.126 \pm 1.315 \mathrm{KBq} / \mathrm{Kg}$ to $30.374 \pm 3.331 \mathrm{KBq} / \mathrm{Kg}$ with a mean value of $17.881 \pm 7.019 \mathrm{KBq} / \mathrm{Kg}$. A comparison of radon concentration in soil samples from different location around the world presented in table 5 shows clearly that the radon concentration in soil samples in Jalingo metropolis is within the safety limit. Figure 2, the plot of Ra-226 against Rn-222 shows a strong positive correlation between Ra226 and $\mathrm{Rn}-222$. This implies that the radon gas in the soil comes from Ra-226.

\section{Conclusion}

The result obtained indicates that the average activity concentration of ${ }^{266} \mathrm{Ra}$ and ${ }^{232} \mathrm{Th}$ is less than world average value of 35 and 30 $\mathrm{Bq} / \mathrm{kg}$ while that of ${ }^{40} \mathrm{~K}$ is higher than the average world value for soil samples [1]. Findings further revealed that all the radiological indices are within the safety limits [1]. Though, the activity concentration and radon gas concentration in surface soils within the region are relatively low but continues exposure to these radiations may cause severe health hazards to the inhabitants of Jalingo metropolis. 


\section{References}

Ajayi, O.S., (2009). Radiation and Environmental Biophysics 48(3):323-332.

Aladeniyi K. and Aladenika A. K. (2015). Radiological study of sachet-packaged water: A case study of the products in Owo local government area of Ondo State, Nigeria. Journal of Radiological Protection 35(3):N19-N24

Cember, H., \&Johnson, T. E. (2012). Introduction to health physics. Health Physics, 102. doi:10.1097/01.HP.0000410056.48665.1f

Chinnaesakki, S., Chopra, M., Kumar, S., Arora, V., Sartandel, S. J., Bara, S. V., Bajwa, B. S. (2011). Assessment of natural radioactivity in soil samples and comparison of the direct and indirect measurement of environmental air kerma rate. Journal of Radioanalytical and Nuclear Chemistry, 289, 885-892.

Darko E. O., Faanu A., Razak A., Emi-Reynolds G., Yeboah J., Oppon O. C. and Akaho E. H. K., (2010). Public exposure hazards associated with natural radioactivity in open-pit mining in Ghana. Rad. Prot, Dosim., 138(1): 45-51.

Ishimori, Y., Lange, K., Martin, P., Mayya, Y.S., Phaneuf, M., 2013. Measurement and Calculation of Radon Releases from NORM
Residues. Technical reports series No. 474. International Atomic Energy Agency, Vienna.

Kaul, A., Becker, D., Brix, G., Dalheimer, A., Dietze, G., Doerfel, H. R., Weiss, W. (2005). Group VIII: Advanced materials and technologie - Radiological protection. (A. Kaul\& D. Becker, Eds.). Berlin: SpringerVerlag.

Mann, S., Ker, G., Eden-Mann, P., \& O'Brien, R. (2017). Designing for Heutagogy: Case Study of an Independent Learning Pathway Approach.

Nada A,(2004).-Gamma Spectroscopic Analysis for Estimation of Natural Radioactivity Levels in Some Granite Rocks of Eastern Desert, Egypt,\| Cairo Arab Journal of Nuclear Science and Application, 37(2):201- 222

National Population Commission (2006). Interim Report of the 2006 National Population Census Exercise.

UNSCEAR., (2008). Sources and Effects and Risks of Ionizing Radiation, IUnited Nations Scientific Committee on the Effects of Atomic Radiation sources, Report to the General Assembly, with Scientific Annexes, United Nations, New York 